\title{
ACUTE PERITONEAL DIALYSIS IN NEONATES WITH ACUTE KIDNEY INJURY AND HYPERNATREMIC DEHYDRATION
}

\author{
Nurdan Yildiz, Müferet Erguven, ${ }^{1}$ Metin Yildiz, ${ }^{2}$ Tutku Ozdogan, ${ }^{1}$ and Pınar Turhan \\ Department of Pediatric Nephrology ${ }^{1}$ and Department of Neonatology, Pediatric Endocrinology, and \\ Metabolism, ${ }^{2}$ Göztepe Teaching and Research Hospital, Istanbul, Turkey
}

- Objective: We aimed to evaluate the efficacy of acute peritoneal dialysis (PD) and clinical outcomes in neonates with acute kidney injury (AKI) and hypernatremic dehydration. - Methods: The medical records of 15 neonates with AKI and hypernatremic dehydration who were treated with acute PD were reviewed. The diagnoses were AKI with hypernatremic dehydration with or without sepsis in 13 patients and AKI with hypernatremia and congenital nephropathy in 2 patients. The main indications for PD were AKI with some combination of oligoanuria, azotemia, hyperuricemia, and metabolic acidosis unresponsive to initial intensive medical treatment.

- Results: The mean age of the patients at dialysis initiation was $11.9 \pm 9$ days, and the mean duration of PD was $6.36 \pm 4.8$ days. In 7 patients $(46.7 \%)$, hypotension required the use of vasopressors, and in 6 patients (40\%), mechanical ventilation was required. Peritoneal dialysisrelated complications occurred in 7 patients $(46.7 \%)$, the most common being catheter malfunction $(n=6)$. Four episodes of peritonitis occurred in the 15 patients (26.7\%), 2 episodes in patients with congenital renal disease and 2 episodes in patients with sepsis and multiorgan failure, who did not survive. Congenital renal disease, septicemia, and the need for mechanical ventilation were important factors influencing patient survival. All patients with no pre-existing renal disease or sepsis recovered their renal function and survived.

- Conclusions: In neonates with AKI and hypernatremic dehydration, PD is safe and successful, and in patients without congenital renal disease or sepsis, the prognosis is good. Peritoneal dialysis should be the treatment of choice in neonates with AKI and hypernatremic dehydration who do not respond to appropriate medical treatment.

Perit Dial Int 2013; 33(3):290-296 www.PDIConnect.com epub ahead of print: 01 Nov 2012 doi:10.3747/pdi.2011.00211

Correspondence to: N. Yildiz, Atasehir 48. Ada, Mimoza 2/6 D: 11, Atasehir, Istanbul, Turkey.

nurdan.yildiz@marmara.edu.tr, nbilgenyildiz@gmail.com

Received 27 August 2011; accepted 5 May 2012
KEYWORDS: Acute kidney injury; hypernatremic dehydration; neonates.

$\Delta$ cute kidney injury (AKI) in neonates has many causative factors. Hypernatremic dehydration associated with breastfeeding is one such cause. Although successful breastfeeding provides compelling advantages to infants and mothers, inadequate breastfeeding may result in lifethreatening dehydration. Hypernatremic dehydration is a rare complication of breastfeeding $(1,2)$, but recent reports have shown that its incidence is increasing (2-5). Prolonged hypovolemia and decreased renal perfusion can cause intrinsic renal injury.

Once intrinsic renal failure becomes established, treatment of the metabolic complications of AKI involves appropriate management of fluid, electrolytes, and acidbase balance; provision of good nutrition; and initiation of renal replacement therapy (RRT) if conventional therapy fails to control metabolic complications and fluid overload (6). The preferential use of hemodialysis (HD) and hemofiltration by pediatric nephrologists is increasing, but those modalities are technically difficult procedures. The large extracorporeal circuit volumes, anticoagulation, and vascular access required are limiting factors, particularly in neonates. As a result, peritoneal dialysis (PD) is generally the most common form of RRT in young children, including neonates, the advantages being relative ease of access and technical simplicity $(6,7)$. Acute PD can easily be performed in units with no HD expertise, and it is effective for the management of AKI and metabolic disturbances in children of all ages, including newborns and preterm infants (8).

The present retrospective study aimed to evaluate the efficacy of acute PD and clinical outcomes in neonates with AKI and hypernatremic dehydration.

\section{METHODS}

Between September 1999 and December 2008, 15 critically ill neonates with AKI and hypernatremia 
followed in our neonatal intensive care unit (NICU) were treated with acute PD.

The medical records of these patients were retrospectively reviewed for age, underlying disease, type of catheter placed, indications for and duration of dialysis, blood pressure, requirement for vasopressor support, complications, and dialysis outcome. All patients were breastfed term infants. Assessment of the adequacy of breastfeeding included a careful review of the feeding process and an objective assessment of weight loss calculated from birth weight and weight on admission. Renal Doppler ultrasonography was performed in all neonates.

All patients were treated initially with isotonic saline solution delivered intravenously at a dose of $10-20 \mathrm{~mL} /$ kg over 1 hour, twice. Fluid therapy, calculated according to the degree of dehydration, was then continued. Furosemide was added if diuresis was not observed within a few hours. The degree of dehydration was estimated from the difference between birth weight and weight on admission. Serum electrolytes were monitored closely to follow the predicted fall in serum sodium during therapy. The recommendation is to correct serum sodium by no more than $15 \mathrm{mEq} / \mathrm{L}$ in 24 hours. The decision to begin dialysis was made if, after at least 12 hours, conservative management failed to control fluid and electrolyte balance.

The main indications for initiating PD included

- severe oligoanuria (decrease in hourly urine output to less than $0.5 \mathrm{~mL} / \mathrm{kg}$ for more than 12 hours) despite fluid therapy, diuretics, and inotropic support;

- hypervolemia (physical evidence of total body fluid overload, edema);

- hyperuricemia ( $\geq 13 \mathrm{mg} / \mathrm{dL}$ );

- severe metabolic acidosis despite bicarbonate therapy; and

- azotemia.

A single-cuff straight Tenckhoff catheter $(n=11)$ or a curled catheter $(n=4)$ was inserted surgically under general anesthesia in all except 2 neonates, in whom the catheters were inserted percutaneously at bedside. The catheter was placed in the left lower quadrant, and dialysis was initiated at a volume of $10 \mathrm{~mL} / \mathrm{kg}$, increased up to $30-40 \mathrm{~mL} / \mathrm{kg}$ as tolerated. Standard lactate-buffered solutions with a glucose concentration of $1.36 \%$ or $2.27 \%$ were used, and dwell times ranged from 30 minutes to 60 minutes. Heparin and antibiotics were administered as clinically needed. In most cases, dialysis exchanges were performed manually by the nursing staff using modified intravenous lines. When available, a PAC-Xtra automated
PD cycler and a HomeChoice automated PD system (both Baxter Healthcare Corporation, Deerfield, IL, USA) were used if the fill volume reached a minimum of $50-100 \mathrm{~mL}$.

Catheter obstruction was defined as slow drainage of the dialysis fluid in either direction, requiring catheter manipulation, irrigation, or reinsertion.

Pericatheter leakage of dialysate was defined as a need for frequent catheter exit-site dressing changes because of soaking.

Peritonitis was defined as a leucocyte count greater than $100 / \mathrm{mm}^{3}$ with $50 \%$ or more polymorphs in the presence of cloudy fluid, with or without organisms in gram-stain or culture, or as symptoms of peritoneal inflammation.

\section{STATISTICAL ANALYSIS}

Data are expressed as mean \pm standard deviation. The Fisher exact test was used to analyze relations between the survival rate and clinical findings and complications. Values of $p$ less than 0.05 were accepted as significant.

\section{RESULTS}

All 15 neonates with AKI and hypernatremic dehydration treated with PD in our NICU were breastfed term infants. All had been admitted with clinical manifestations of hypernatremic dehydration (serum sodium > $150 \mathrm{mmol} / \mathrm{L}$ ). There was no explanation for the hypernatremia (such as vomiting and diarrhea), other than inadequate breast-milk intake.

Table 1 summarizes the characteristics of the patients. The diagnosis was AKI with hypernatremic dehydration and anuria with or without sepsis in 13 patients, AKI with congenital nephropathy in 1 patient (patient 10), and autosomal recessive polycystic kidney disease in 1 patient (patient 11). All infants were more than 38 weeks of gestational age. Mean birth weight was $3096.7 \pm 143 \mathrm{~g}$, and mean weight on admission was $2742.8 \pm 114.7 \mathrm{~g}$. The mean percentage weight loss was $11.4 \% \pm 1.7 \%$ (range: $9.5 \%-14.4 \%)$. Mean age at dialysis start was $11.9 \pm 9$ days. The mean duration of PD was $6.36 \pm 4.8$ days (range: 1 - 21 days).

Laboratory findings on admission included a mean pre-dialysis serum creatinine $(\mathrm{Cr})$ of $5.9 \pm 1.7 \mathrm{mg} /$ $\mathrm{dL}$ (range: $2-8.8 \mathrm{mg} / \mathrm{dL}$ ), a mean sodium level of $169.2 \pm 6.5 \mathrm{mmol} / \mathrm{L}$ (range: $158-180 \mathrm{mmol} / \mathrm{L}$ ), a mean uric acid level of $21.5 \pm 8.4 \mathrm{mg} / \mathrm{dL}$ (range: $6.3-40 \mathrm{mg} /$ $\mathrm{dL}$ ), and a potassium level of $6.3 \pm 1.3 \mathrm{mmol} / \mathrm{L}$ (range: $3.5-8 \mathrm{mmol} / \mathrm{L})$. 
TABLE 1

Clinical and Laboratory Features of the Patients at Presentation

\begin{tabular}{|c|c|c|c|c|c|c|c|c|c|c|c|c|}
\hline $\begin{array}{l}\mathrm{Pt} \\
\text { ID }\end{array}$ & $\begin{array}{l}\text { Age } \\
\text { (days) }\end{array}$ & Sepsis & $\begin{array}{l}\text { Ventil- } \\
\text { ation }\end{array}$ & Oliguria & $\begin{array}{l}\text { Inotropic } \\
\text { support }\end{array}$ & $\begin{array}{l}\text { Convul- } \\
\text { sions }\end{array}$ & $\begin{array}{c}\mathrm{Cr} \\
(\mathrm{mg} / \mathrm{dL})\end{array}$ & $\begin{array}{c}\mathrm{UA} \\
(\mathrm{mg} / \mathrm{dL})\end{array}$ & $\begin{array}{c}\mathrm{Na} \\
(\mathrm{mEq} / \mathrm{L})\end{array}$ & $\begin{array}{c}\mathrm{K} \\
(\mathrm{mEq} / \mathrm{L})\end{array}$ & Acidosis & Outcome \\
\hline 1 & 7 & & & Yes & & Yes & 3.9 & 28.6 & 173 & 5 & Yes & Survived \\
\hline 2 & 8 & & & Yes & & Yes & 7.27 & 26 & 180 & 6.5 & Severe & Survived \\
\hline 3 & 9 & & & Yes & & Yes & 7.4 & 19 & 165 & 7.4 & & Survived \\
\hline 4 & 30 & & & Yes & & & 5.7 & 21 & 165 & 7.27 & & Survived \\
\hline 5 & 7 & & & Yes & Yes & Yes & 5.8 & 40 & 179 & 7.9 & Yes & Survived \\
\hline 6 & 5 & Yes & Yes & Yes & Yes & Yes & 4.57 & 29.1 & 172 & 7.2 & Yes & Died \\
\hline 7 & 4 & Yes & Yes & Yes & & & 6.1 & 23.3 & 172 & 5.8 & Yes & Survived \\
\hline 8 & 7 & & & Yes & Yes & & 8.8 & 21 & 174 & 8 & Yes & Survived \\
\hline 9 & 27 & Yes & Yes & Yes & & Yes & 4.1 & 13 & 160 & 5.4 & Severe & Died \\
\hline $10^{\mathrm{a}}$ & 15 & Yes & Yes & Yes & Yes & & 5.7 & 8.9 & 165 & 5.3 & & Died \\
\hline $11^{b}$ & 4 & Yes & Yes & Yes & & & 2 & 6.3 & 165 & 3.5 & Yes & Died \\
\hline 12 & 9 & & & Yes & Yes & & 8 & 17 & 158 & 7.5 & Yes & Survived \\
\hline 13 & 27 & Yes & & Yes & & & 5.5 & 25 & 165 & 6.8 & & Survived \\
\hline 14 & 15 & & & Yes & Yes & Yes & 6.5 & 20 & 170 & 5.9 & Yes & Survived \\
\hline 15 & 4 & Yes & Yes & Yes & Yes & Yes & 6.8 & 24 & 175 & 5.5 & Yes & Survived \\
\hline
\end{tabular}

$\mathrm{Pt}=$ patient $; \mathrm{Cr}=$ creatinine; $\mathrm{UA}=$ uric acid.

a Patient with congenital nephropathy

b Patient with autosomal recessive polycystic kidney disease.

Renal ultrasonography revealed increased renal parenchymal echogenicity in 10 patients and bilateral renal cysts in 1 patient.

Hourly urine output increased gradually from $0.5 \mathrm{~mL} / \mathrm{kg}$ to $4.7 \mathrm{~mL} / \mathrm{kg}$ during dialysis treatment. The increased urinary output was accompanied by a fall in serum $\mathrm{Cr}$ to $0.5 \pm 0.2 \mathrm{mg} / \mathrm{dL}$. Serum sodium declined to $160.8 \pm 6.7 \mathrm{mg} / \mathrm{dL}$ (range: $152-170 \mathrm{mg} / \mathrm{dL}$ ) at the end of 24 hours and to $152 \pm 7.1 \mathrm{mg} / \mathrm{dL}(142-163 \mathrm{mg} / \mathrm{dL})$ after 48 hours. In all patients, serum sodium did not decline more than $15 \mathrm{mEq} / \mathrm{L}$ per day, which is the accepted 1-day reduction target.

All patients were dehydrated and oligoanuric on admission and did not respond to appropriate fluid therapy for at least 12 hours. Progressive azotemia with oligoanuria was present in 15 patients $(100 \%)$; hyperuricemia ( $\geq 13 \mathrm{mg} / \mathrm{dL})$, in 13 patients $(86.7 \%)$; hyperkalemia ( $\geq 6.5 \mathrm{mmol} / \mathrm{L})$, in 8 patients $(53.3 \%)$; and intractable acidosis, in 11 patients $(73.3 \%)$.

Infusions of inotropic agents-specifically, dopamine with or without dobutamine for hypotension and hemodynamic instability in critical illness-were given to 7 patients (46.7\%). Early mechanical ventilation was required in 6 patients (40\%). Seizures were present in 8 infants $(53.3 \%)$ at admission. At presentation, 7 infants $(46.7 \%)$ were evaluated and empirically treated for sepsis; treatment was then revised according to the culture results.

\section{COMPLICATIONS}

Afebrile convulsions occurred in 8 patients (53.3\%) on admission. No other serious complications of severe dehydration (such as thrombosis, intracranial hemorrhage, and necrotizing enterocolitis) occurred.

Complications related to PD occurred in 7 patients (46.7\%): dialysate leak in 2, exit-site bleeding in 1 , catheter migration in 1 , and catheter blockade by fibrin or omentum in 3. Catheter replacement was performed in 2 patients ( 1 because of leakage, 1 because of occlusion). In 2 patients with a percutaneously inserted Tenckhoff catheter, one experienced catheter-related complications and exit-site bleeding, and the other experienced leakage and peritonitis.

Four episodes of peritonitis occurred (26.7\%). The isolated micro-organisms included 1 methicillinresistant Staphylococcus aureus, 1 Klebsiella, and 1 Candida albicans. One episode was culture-negative. The suspected reasons for peritonitis were leakage in 2 patients, catheter migration in 1 patient, and unspecified in 1 patient.

\section{OUTCOMES}

Significant comorbidities were present in 12 infants, and 4 did not survive $(26.7 \% ; 2$ with congenital nephropathy and autosomal recessive polycystic kidney 
disease with sepsis, 2 with sepsis and multiorgan failure). Table 2 summarizes clinical and laboratory findings in the survivors and non-survivors.

All non-survivors required mechanical ventilation. The mortality rate was highest in patients requiring mechanical ventilation ( 4 of 6 patients, $66.7 \%$ ), and next highest in those with septicemia ( 4 of 7 patients, $57.1 \%$; $p>0.05)$. Peritoneal dialysis-related complications were managed successfully, and no deaths were attributable to peritonitis or other PD-related complications.

Eleven patients with AKI and no pre-existing renal disease recovered renal function and survived (73.3\%). Most survivors did not require mechanical ventilation $(n=9)$ and had no septicemia $(n=8)$. The survival rate was $100 \%$ in non-septic patients and $42.9 \%$ in septic patients. All patients with normal blood pressure and 5 of 7 patients

TABLE 2

Clinical and Laboratory Findings in Survivors and Non-survivors

\begin{tabular}{|c|c|c|c|}
\hline \multirow[b]{2}{*}{ Variable } & \multicolumn{2}{|c|}{ Survived? } & \multirow{2}{*}{$\begin{array}{c}p \\
\text { Value }\end{array}$} \\
\hline & Yes & No & \\
\hline Patients $(n)$ & 11 & 4 & \\
\hline \multicolumn{4}{|l|}{ Age (days) } \\
\hline Mean & $11.5 \pm 8.9$ & $12.8 \pm 10.7$ & \\
\hline Range & 4-30 & 4-27 & \\
\hline \multicolumn{4}{|l|}{ Creatinine (mg/dL) } \\
\hline Mean & $6.5 \pm 1.3$ & $4.1 \pm 1.5$ & \\
\hline Range & $3.9-8.8$ & $2-5.7$ & \\
\hline \multicolumn{4}{|l|}{$\mathrm{Na}(\mathrm{mEq} / \mathrm{L})$} \\
\hline Mean & $170.5 \pm 6.7$ & $165.5 \pm 4.9$ & \\
\hline Range & $158-180$ & $160-172$ & \\
\hline \multicolumn{4}{|l|}{$\mathrm{K}(\mathrm{mEq} / \mathrm{L})$} \\
\hline Mean & $6.7 \pm 1$ & $5.4 \pm 1.5$ & \\
\hline Range & $5-8$ & $3.5-7.2$ & \\
\hline \multicolumn{4}{|l|}{ Uric acid (mg/dL) } \\
\hline Mean & $24.1 \pm 6.2$ & $14.3 \pm 10.2$ & \\
\hline Range & $17-40$ & $6.3-29.1$ & \\
\hline Convulsions $[n(\%)]$ & $6(54.5)$ & $2(50)$ & 0.88 \\
\hline Acidosis [ $n(\%)]$ & $8(72.7)$ & $3(75)$ & 0.93 \\
\hline Septicemia [n (\%)] & $3(27.3)$ & $4(100)$ & 0.03 \\
\hline $\begin{array}{l}\text { Mechanical } \\
\text { ventilation }[n(\%)]\end{array}$ & 2 (18.2) & $4(100)$ & 0.01 \\
\hline $\begin{array}{l}\text { Hypotension } \\
\text { with vasopressor }\end{array}$ & & & \\
\hline $\begin{array}{l}\text { use }[n(\%)] \\
\text { Complications }(n)\end{array}$ & $5(45.5)$ & $2(50)$ & 0.66 \\
\hline Exit-site bleeding & 0 & 1 & \\
\hline Malfunction ${ }^{\mathrm{a}}$ & 4 & 2 & 0.96 \\
\hline Replacement & 1 & 1 & \\
\hline Peritonitis & 3 & 1 & 0.98 \\
\hline
\end{tabular}

${ }^{a}$ Dialysate leakage or obstruction by fibrin or omentum. with low blood pressure receiving vasopressor therapy survived. Factors influencing patient survival included septicemia, requirement for mechanical ventilation, and pre-existing congenital renal disease (Table 2).

\section{DISCUSSION}

In newborns, AKI is common and has many causative factors. Most patients have prerenal failure associated with an underlying disease, some have had heart surgery, and a few have congenital renal malformations $(6,7,9)$. Hypernatremic dehydration is a rarer cause of prerenal AKI in neonates. Prolonged hypovolemia and decreased renal perfusion can cause intrinsic renal injury. Severe hypernatremic dehydration can occur as a result of inadequate milk intake $(2,4,10)$. In our patients, there was no explanation (such as diarrhea or vomiting) other than inadequate milk intake for hypernatremia, with a mean weight loss of $11.4 \%$. However, our patient population included 2 patients with pre-existing renal disease, both of whom were oligoanuric at presentation. Those infants might have had high urine output because of their primary renal disease and might have been more prone to dehydration. However, the parents provided no information, such as increased daily diaper use, to assess polyuria. The incidence of hypernatremic dehydration in breastfed neonates has been reported to be $1.9 \%-7.7 \%$ $(2,3,4)$. It was found to be about $4.1 \%-5.6 \%$ in Turkey $(11,12)$. Although hypernatremic dehydration is rare in neonates and infants, there have been reports of severe complications and an increasing incidence of hypernatremic dehydration in breastfed neonates $(4,5,10,11)$.

Acute kidney injury is a complex disorder that occurs with variable severity. No universal definition of AKI is recognized in neonates. Our diagnoses relied on two functional abnormalities: high serum $\mathrm{Cr}$ and oligoanuria unresponsive to initial isotonic saline and furosemide therapy for 12 hours. Both of those parameters are late consequences of injury. There was no doubt about the diagnosis of AKI in our patients given mean $\mathrm{Cr}$ levels of $5.9 \mathrm{mg} / \mathrm{dL}$, but it was difficult to differentiate whether AKI was prerenal or intrinsic. We could not measure urinary indices-including urine sodium, density, or osmolality-that have been proposed for differentiating prerenal injury from acute tubular necrosis because all patients were oligoanuric on admission, and collecting urine was not possible. We initiated PD promptly to control hypernatremia and other metabolic comorbidities such as severe hyperuricemia that might contribute to further intrinsic renal injury. Hypervolemia then developed because of the combination of aggressive fluid therapy and oligoanuria. 
We suggest that the decision for dialysis should not be delayed in infants (13). Early initiation of PD in infants who developed ischemic AKI after surgical repair of congenital heart disease showed that the shorter the time from ischemic insult to dialysis start, the higher the survival rate (14).

Patients with oligoanuric AKI need RRT when conservative therapy fails to control complications $(6,7)$. Despite technological progress and increased preferential use of HD and hemofiltration by pediatric nephrologists $(15,16), P D$ is still the modality of choice in most neonates and small infants because of problems of vascular access, coagulation control, and technical difficulties with the former modalities $(6,7,9,17,18)$. Acute PD can easily be performed in units with no HD expertise, and it is effective in the management of AKI in children of all ages, including neonates and preterm and low-birthweight infants $(8,18-21)$.

Although the 15 neonates with AKI and hypernatremic dehydration reported here represent a small number of patients, our series is the largest to date on such patients treated with PD. At our center, technical difficulties do not allow us to perform HD for small infants and neonates, and therefore all are treated with $\mathrm{PD}$.

In newborns, prognosis of and recovery from AKI highly depend on the underlying cause and any medical problems, not on complications of PD $(9,18,20,21)$. Factors associated with mortality include multiorgan failure, hypotension, need for vasopressor therapy, hemodynamic instability, and requirement for mechanical ventilation and dialysis $(16,18,20,22)$. In our series, patients with oliguric AKI that could not be corrected using fluid challenge and furosemide infusion had a poorer prognosis than did patients with nonoliguric AKI. All our AKI patients presented with oligoanuria, severe hypernatremia, marked increase in plasma $\mathrm{Cr}$, and hyperuricemia. They were unresponsive to initial treatment using a bolus of isotonic saline solution and furosemide. Peritoneal dialysis was successful in controlling fluid overload, hyperkalemia, hypernatremia, and acidosis in our patients. The overall mortality rate was $26.7 \%$. Mortality was associated with the severity of the original disease. The mortality rate was higher in patients with septicemia and multiorgan failure. Survival was $100 \%$ in non-septic patients compared with $42.9 \%$ in septic patients in our series. Hemodynamic instability requiring vasoactive pressor support did not affect the survival rate. Peritoneal dialysis-related complications were managed successfully, and no deaths attributable to peritonitis or other PD-related complications occurred.

In our series, serum sodium did not show an abrupt fall, which could lead to cerebral edema. Treatment using standard lactate-buffered PD solutions (with $132 \mathrm{mEq} / \mathrm{L}$ sodium) corrected serum sodium by no more than $15 \mathrm{mEq} / \mathrm{L}$ in 24 hours in our patients. Several case reports have presented the use of PD to treat hypernatremia in children (23-25). Moritz et al. reported an infant with multiorgan failure who developed severe hypernatremia because of rapid free-water removal with acute PD. However, PD treatment with low-sodium hypertonic solution was also used to correct hypernatremia and fluid overload in that infant (23). In the other reports, the need for fluid removal was not a consideration, and serum sodium was corrected with the contribution of free water administration $(24,25)$. In our series, patients were oligoanuric and hypervolemic because of intensive intravenous fluid therapy to restore intravascular volume. Thus, one of the main goals of PD was fluid removal. We achieved both fluid and sodium removal using standard dialysis solutions (Dianeal: Baxter Healthcare Corporation, Deerfield, IL, USA) in our patients.

Congenital renal disease with chronic renal failure, usually caused by renal dysplasia with or without obstruction, presents in a manner similar to that of acute renal failure, with progressive deterioration of plasma biochemical values. Autosomal recessive polycystic kidney disease occasionally causes renal failure in the neonatal period, but only in a small proportion of patients (7). We could not distinguish whether our 2 patients with congenital renal disease had chronic renal insufficiency because they had not previously been clinically evaluated. However, these infants had a history of inadequate milk intake, were severely dehydrated, and had recently become anuric, with high serum sodium on admission. We therefore thought that these infants had acute deterioration of renal function and hypernatremic dehydration. Underlying renal diseases may have facilitated the development of AKI, and the prognosis for both infants was poor.

Reported complications of PD in infants include peritonitis, leakage at the exit-site, catheter obstruction requiring revision or replacement, and in several case reports, bowel perforation (7-9). We did not observe any life-threatening PD related complications in our patients. Survival in our patients was related to underlying medical problems, not to complications of PD. Peritoneal dialysisrelated complications occurred in $46.7 \%$ of the patients and were successfully managed, allowing for resumption of effective dialysis. Both patients with a percutaneously placed Tenckhoff catheter underwent catheter replacement because of exit-site bleeding, catheter blockage, and leakage. Surgically placed cuffed Tenckhoff catheters provided good immediate function and a lower complication rate. They were also found to be more effective 
than percutaneously inserted catheters $(22,26)$. It is suggested that a Tenckhoff catheter be considered once dialysis is expected to extend beyond 5 days (23).

It is important that the dialysis modality used in treating AKI be safe, effective, and affordable. Peritoneal dialysis is the preferred dialysis modality in neonates not only because of its technical simplicity, but also because of its cost-effectiveness. For the dialysis procedure alone, the cost of PD has been found to be about one third the cost of HD and one quarter the cost of continuous arteriovenous hemodiafiltration (27). Experience in our NICU proves that acute PD is safe and might reduce both morbidity and mortality in patients with AKI and hypernatremic dehydration. At the end of the dialytic period, all the survivors regained normal renal function.

Our study has some limitations. First, long-term follow-up of the infants was not possible in our center after discharge, because all came from various regions and urban areas. We therefore cannot report long-term renal and neurologic outcomes. Another limitation is that the present study does not include patients with AKI and hypernatremia corrected by medical treatment. Those infants were followed in the NICU by a neonatologist; only severe cases unresponsive to initial medical treatment who needed RRT were sent for consultation to the pediatric nephrologist. In addition, for ethical reasons, we did not create a control group with similar characteristics. It is difficult to leave a patient without RRT who needs it. This paper was planned as retrospective single-center study. Although our study constitutes the largest series reported to date, the small number of patients limits our ability to make precise inferences. Large multicentric prospective studies would be needed. Our expectation is that our report will pioneer studies in the field, and larger multicentric studies will follow.

\section{CONCLUSIONS}

Acute PD is safe and successful for the management of severe AKI with hypernatremic dehydration in neonates, and the prognosis is good for infants without congenital renal disease or sepsis. Peritoneal dialysis should be considered the dialysis modality of choice in neonates with AKI and hypernatremic dehydration who do not respond to appropriate medical treatment, especially in units with less HD expertise and lack of access to the technical capacity.

\section{DISCLOSURES}

The authors have no conflicts of interest or disclosures related to this manuscript.

\section{REFERENCES}

1. Neifert MR. Prevention of breastfeeding tragedies. Pediatr Clin North Am 2001; 48:273-97.

2. Moritz ML, Manole MD, Bogen DL, Ayus JC. Breastfeedingassociated hypernatremia: are we missing the diagnosis. Pediatrics 2005; 116:e343-7.

3. Oddie S, Richmand S, Coulthard M. Hypernatraemic dehydration and breast feeding: a population study. Arch Dis Child 2001; 85: 18-20.

4. Manganaro R, Mamì C, Marrone T, Marseglia L, Gemelli M. Incidence of dehydration and hypernatremia in exclusively breast-fed infants. J Pediatr 2001; 139:673-5.

5. Laing IA, Wong CM. Hypernatremia in the first few days: is the incidence rising? Arch Dis Child Fetal Neonatal Ed 2002; 87:F158-62.

6. Gouyon JB, Guignard JP. Management of acute renal failure in newborns. Pediatr Nephrol 2000; 14:1037-44.

7. Haycock GB. Management of acute and chronic renal failure in the newborn. Semin Neonatol 2003; 8:325-34.

8. Reznik VM, Griswold WR, Peterson BM, Rodarte A, Ferris $M E$, Mendoza SA. Peritoneal dialysis for acute renal failure in children. Pediatr Nephrol 1991; 5:715-17.

9. Andreoli SP. Acute renal failure in the newborn. Semin Perinatol 2004; 28:112-23.

10. Shroff R, Hignett R, Pierce C, Marks S, van't Hoff W. Lifethreatening hypernatraemic dehydration in breastfed babies. Arch Dis Child 2006; 91:1025-6.

11. Unal S, Arhan E, Kara N, Uncu N, Aliefendioğlu D. Breastfeeding-associated hypernatremia: retrospective analysis of 169 term newborns. Pediatr Int 2008; 50:29-34.

12. Uras N, Karadag A, Dogan G, Tonbul A, Tatli MM. Moderate hypernatremic dehydration in newborn infants: retrospective evaluation of 64 cases. J Matern Fetal Neonatal Med $2007 ; 20: 449-52$.

13. Bonilla-Félix M. Peritoneal dialysis in the pediatric intensive care unit setting. Perit Dial Int 2009; 29(Suppl 2):S183-5.

14. Sorof JM, Stromberg D, Brewer ED, Feltes TF, Fraser CD Jr. Early initiation of peritoneal dialysis after surgical repair of congenital heart disease. Pediatr Nephrol 1999; 13:641-5.

15. Bunchman TE, Donckerwolcke RA. Continuous arterialvenous diahemofiltration and continuous venous venous diahemofiltration in infants and children. Pediatr Nephrol 1994; 8:96-102.

16. Maxvold NJ, Smoyer WE, Gardner JJ, Bunchman TE. Management of acute renal failure in the pediatric patient: hemofiltration versus hemodialysis. Am J Kidney Dis 1997; 30(Suppl 4):S84-8.

17. Flynn JT, Kershaw DB, Smoyer WE, Brophy PD, McBryde KD, Bunchman TE. Peritoneal dialysis for management of pediatric acute renal failure. Perit Dial Int 2001; 21:390-4.

18. Blowey DL, McFarland K, Alon U, McGraw-Houchens M, Hellerstein S, Warady BA. Peritoneal dialysis in the neonatal period: outcome data. J Perinatol 1993; 13:59-64. 
19. Sizun J, Giroux JD, Rubio S, Guillois B, Alix D, De Parscau L. Peritoneal dialysis in the very low-birth-weight neonate (less than $1000 \mathrm{~g}$ ). Acta Paediatr 1993; 82:488-9.

20. Matthews DE, West KW, Rescorla FJ, Vane DW, Grosfeld JL, Wappner RS, et al. Peritoneal dialysis in the first 60 days of life. J Pediatr Surg 1990; 25:110-15.

21. Bunchman TE, McBryde KD, Mottes TE, Gardner JJ, Maxvold NJ, Brophy PD. Pediatric acute renal failure: outcome by modality and disease. Pediatr Nephrol 2001; 16:1067-71.

22. Huber R, Fuchshuber A, Huber P. Acute peritoneal dialysis in preterm newborns and small infants: surgical management. J Pediatr Surg 1994; 29:400-2.

23. Moritz ML, del Rio M, Crooke GA, Singer LP. Acute peritoneal dialysis as both cause and treatment of hypernatremia in an infant. Pediatr Nephrol 2001; 16:697-700.

24. Miller NL, Finberg L. Peritoneal dialysis for salt poisoning. Report of a case. N Engl J Med 1960; 263:1347-50.

25. el-Dahr S, Gomez RA, Campbell FG, Chevalier RL. Rapid correction of acute salt poisoning by peritoneal dialysis. Pediatr Nephrol 1987; 1:602-4.

26. Chadha V, Warady BA, Blowey DL, Simckes AM, Alon US. Tenckhoff catheters prove superior to Cook catheters in pediatric acute peritoneal dialysis. Am J Kidney Dis 2000; 35:1111-16.

27. Reznik VM, Randolph G, Collins CM, Peterson BM, Lemire JM, Mendoza SA. Cost analysis of dialysis modalities for pediatric acute renal failure. Perit Dial Int 1993; 13:311-13. 